\title{
Characteristics of Small Offset Streams Crossing Strike-Slip Faults in Japan
}

\author{
OUCHI Shunji \\ College of Science and Engineering, Chuo University, Tokyo 112-8551, Japan
}

\begin{abstract}
Seven small offset streams crossing strike-slip faults in central to south-western Japan, longitudinal profiles and channel course geometry of which were measured in the field, show no correlation between the amount of channel offset (offset length) and drainage area or channel length above the fault. The method to estimate fault slip rates from the relationship between offset length and channel length above the fault seems not valid for these offset streams. The angle of deflection, which is the angle between the fault line and the reach connecting reaches divided by fault displacement (offset reach), shows a negative correlation with offset length for the streams of long offset, while no correlation is clear for the streams of short offset. When the channel offset is short and significant channel shift towards the steepest possible course does not occur yet, fault zone width probably controls the deflection angle. The negative correlation for the streams of long offset may reflect the easier channel shift of the streams with shorter offset among them. The deformation types of these offset streams are judged as Type A (offset slope of fault displacement is smaller than channel gradient) except for one as Type C with larger offset slope. Some configurations characteristic to the deformation types still remain in their longitudinal profiles with various degrees of fluvial adjustment. Offset streams seem to be in the repeated process of tectonic deformation and fluvial adjustment as long as the fault activity continues.
\end{abstract}

Key words: strike-slip fault, offset stream, longitudinal profile, channel course geometry, fluvial adjustment.

\section{Introduction}

Numerous strike-slip faults cut the Japanese islands, and systematically bended channels (offset channels) are the most common evidence employed to identify these faults (e.g., Kaneko 1965; Matsuda 1966; The Research Group for Active Faults of Japan 1980, 1991). They are supposed to be offset by the fault displacement. However, distinguishing channel deformation associated with fault displacement from channel changes caused by fluvial processes is very difficult. Offset channels (or streams) usually show a variety of configuration, and even a channel crossing a confirmed active strike-slip fault does not necessarily show the offset by fault displacement (e.g., Lensen 1958; Allen 1962; Wallace 1968; Gaudemer et al. 1989; Huang 1993). The development of offset channels seems to be more a complex phenomenon than generally considered, and more studies are certainly required from the viewpoints of both tectonic and fluvial processes. With this perspective in mind, I conducted a series of flume experiments to see the effects of horizontal fault displacement on experimental streams (Ouchi 2004), and discussed the development of offset channels crossing the San Andreas fault, California, based on fieldmeasured channel course geometry and longitudinal profiles (Ouchi 2005). This paper examines the characteristics of small offset streams in Japan, through the analysis of planform channel course geometry and longitudinal profiles measured in the field. 


\section{Measurement and Analysis of Channel Course Geometry and Longitudinal Profiles of Small Offset Streams in Japan}

Channels exhibiting clear offset associated with strike-slip faulting are usually too small to measure their planform geometry and longitudinal profiles accurately on available topographic maps, even on large-scale maps such as 1:5,000; and therefore, the measurements were performed in the field with the same measuring instrument used in the measurement of offset channels crossing the San Andreas fault (Ouchi 2005). Compared with the remote, semi-arid and relatively flat Carrizo Plain, California, the field condition of Japanese offset streams is awfully bad. In the first place, finding offset channels without artificial modification is very difficult; and even if a measurable offset channel is found, dense vegetation, abundant water flows and steep channel floors make accurate field measurements very hard. The number of offset channels analyzed in this study, therefore, is rather small (seven) for the time spent in the field work, and they are scattered over central to south-western Japan, namely, in the Neo Valley, on Miura and Izu Peninsulas, and on Shikoku Island along the Median Tectonic Line (Figure 1). Moreover, reflecting the complex tectonic setting of the Japanese islands, fault systems that appeared on the surface are very complicated and no simple continuous fault offsetting a number of streams in a similar manner could be found. The orientation of a fault line is determined on large-scale topographical maps with the help of the Digital Active Fault Map of Japan (Nakata and Imaizumi 2002), and converted to magnetic orientation for analytical convenience.

The obtained data are plotted in three graphs,

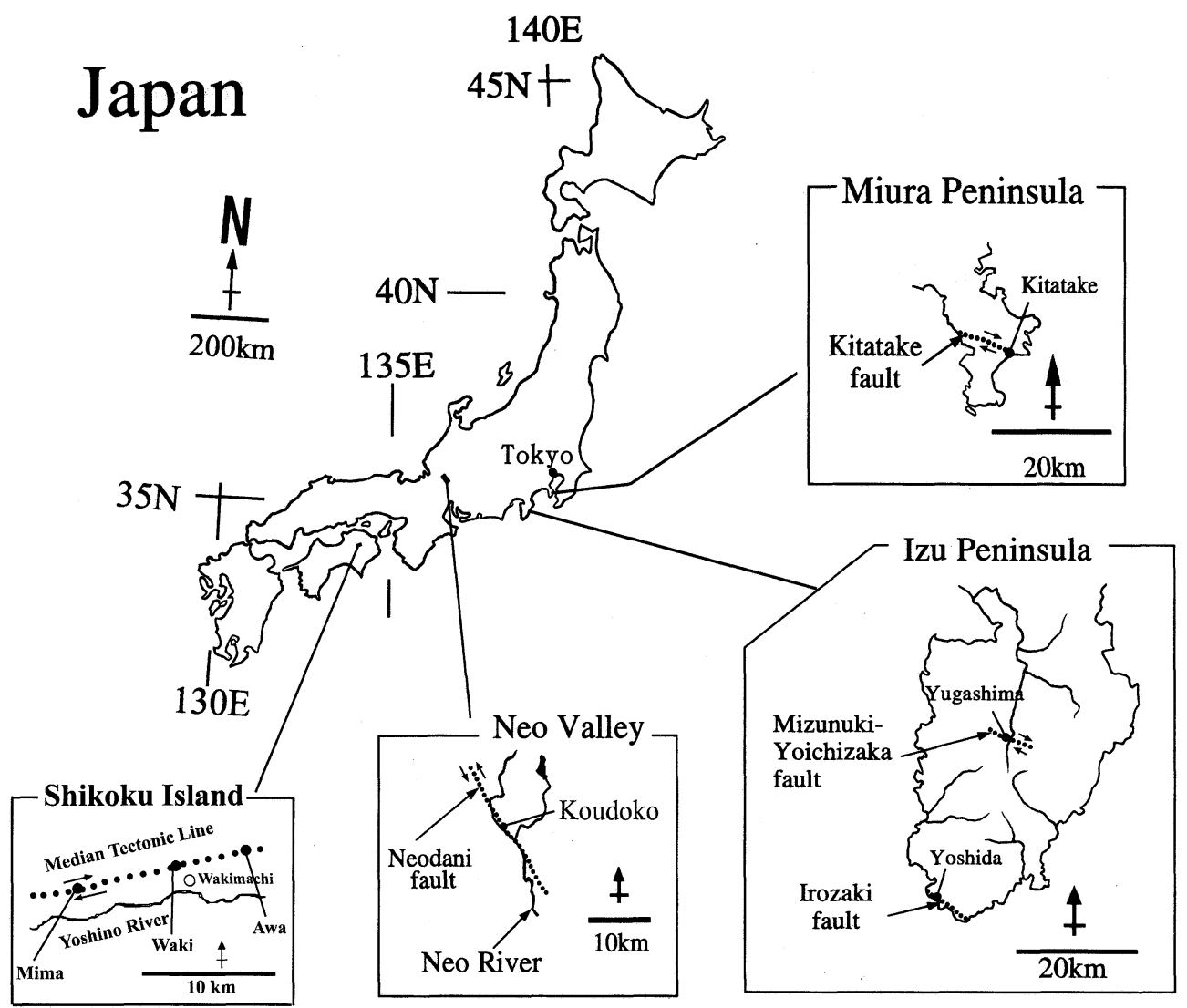

Figure 1. Index map showing the locations of offset streams reported in this study (Kitatake on Miura Peninsula; Koudoko in the Neo Valley; Yoshida and Yugashima on Izu Peninsula; Mima, Waki, and Awa on Shikoku Island). 
plan view (channel course geometry), projected longitudinal profile and longitudinal profile along channel, in the same manner as Ouchi (2005). Definition of geometrical properties (Figure 2) and the method of analysis follow Ouchi (2004) and Ouchi (2005). An "offset reach" is the reach connecting the upstream and downstream reaches divided by horizontal fault displacement. The angle of deflection $(\theta)$ is the angle between the fault slip direction and the offset reach (Huang 1993). For the analysis, regression lines of sections representing three reaches are drawn as upstream, offset and downstream lines on the plan view graph, and parameters are calculated from the equations of these lines. The parameters, such as offset length $(\Delta h)$, which represents the amount of channel offset, presumed channel gradient before the deformation $\left(S_{c}\right)$, and the ratio of vertical $(\Delta v)$ to horizontal $(\Delta h)$ components of fault displacement (offset slope; $S_{o}=\Delta v / \Delta h$ ) are calculated for the upstream reach and the downstream reach separately, because these two reaches are usually not parallel. A line parallel to the fault line is drawn through the intersecting point between the offset and upstream (or downstream) lines on the plan view graph, and is regarded as the upper (or lower, respectively) fault line in the calculation (Figure

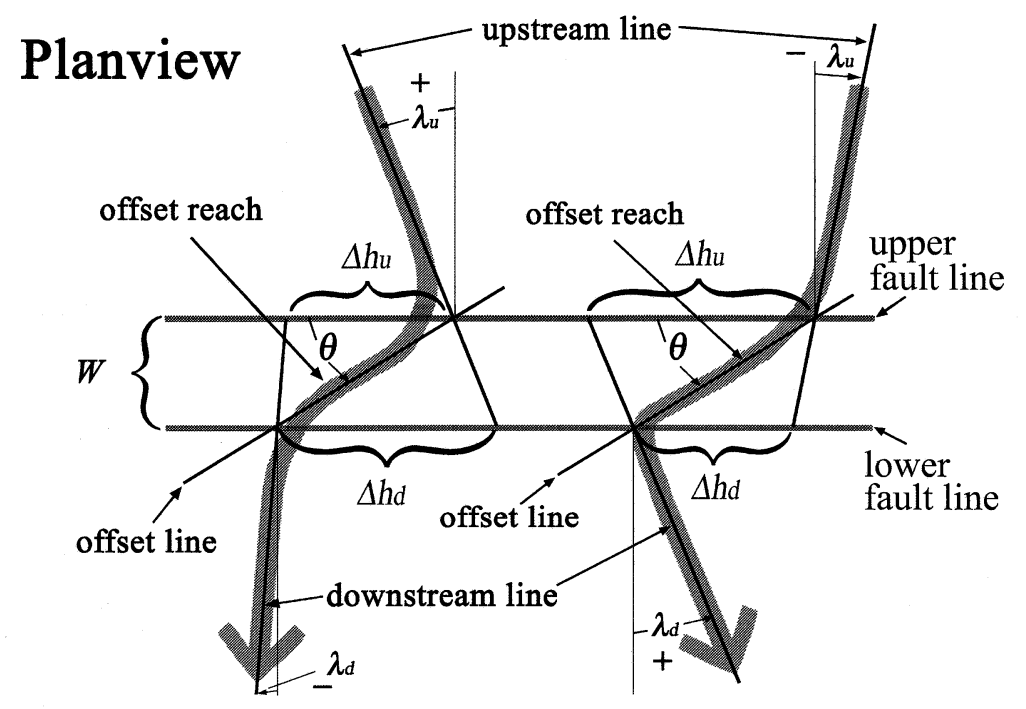

\section{An example of a longitudinal profile along an offset channel}

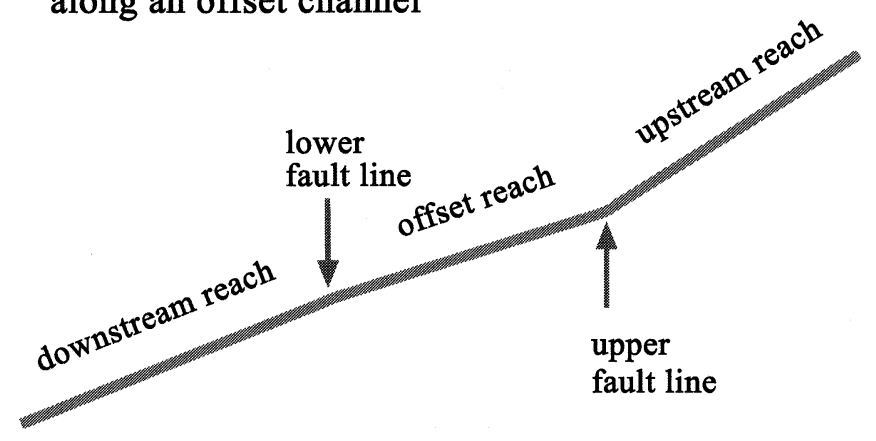

Figure 2. Schematic diagrams illustrating geometrical properties of offset channels and the method of measurement. See the text for details. 
OUCHI S.

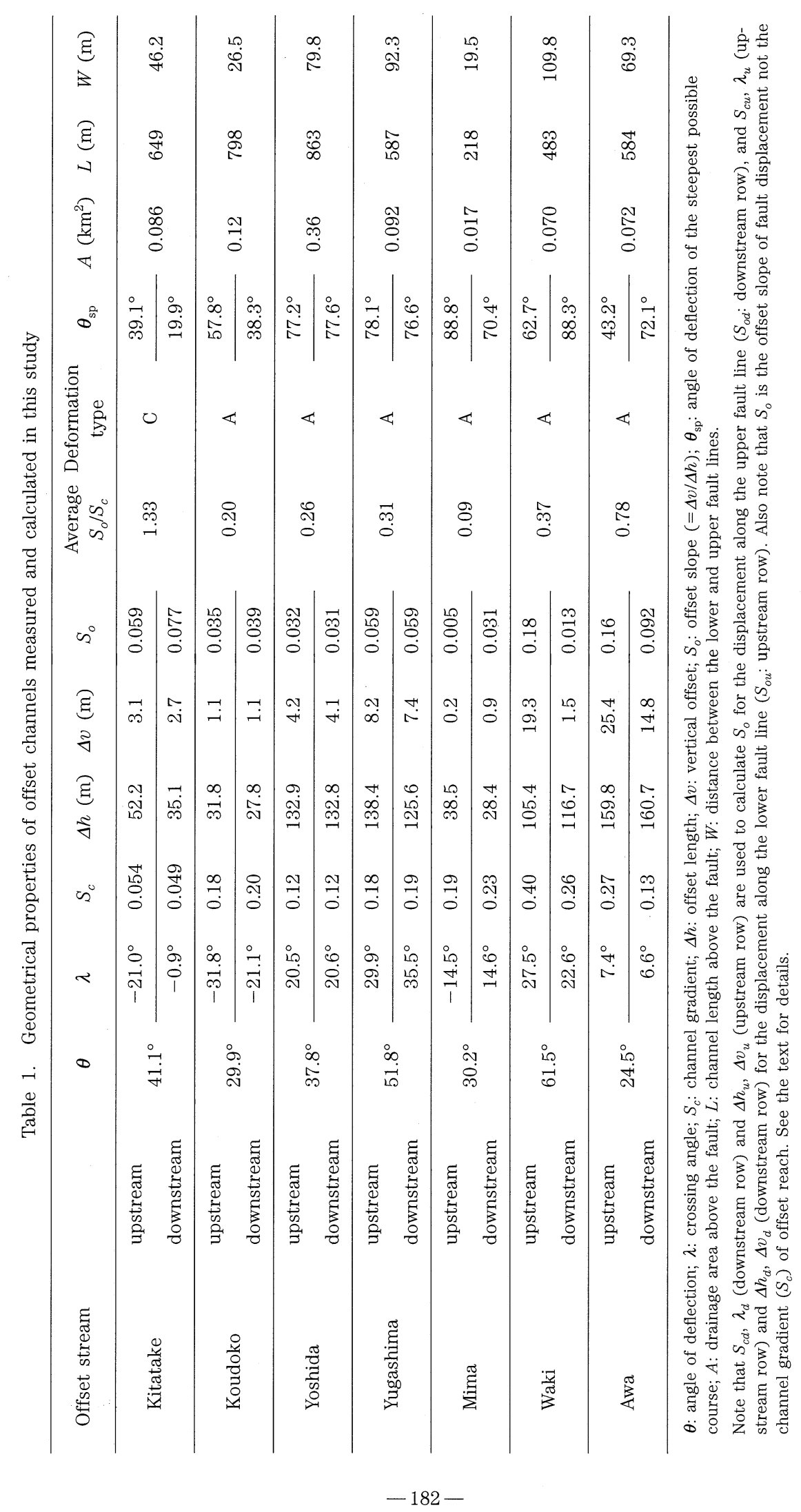




\section{Kitatake}
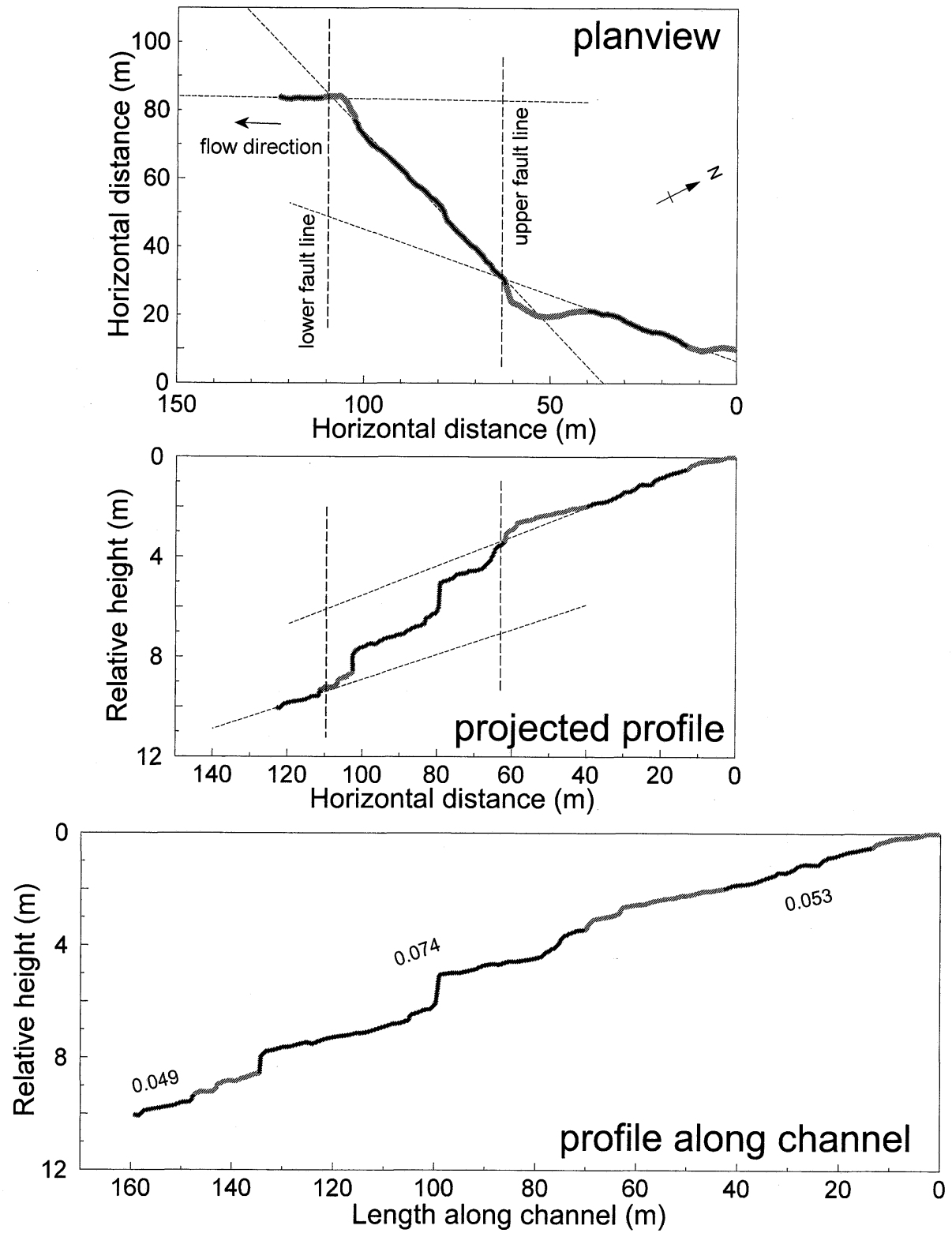

Figure 3. Channel course geometry and longitudinal profiles of Kitatake on Miura Peninsura. The vertical axis of the planview graph is taken parallel to the fault line. Thick dark lines correspond to the representative sections of the upstream, offset, and downstream reaches. The thinner broken lines along the channel course in the planview graph are regression lines of these sections, indicating upstream, offset and downstream lines. The projected longitudinal profile is the longitudinal profile projected onto the plane perpendicular to the fault trace. The numbers in the longitudinal profile along channel graph are the channel gradients $\left(S_{c}\right)$ of these three sections. Note that the number on the offset reach indicates the channel gradient of the reach not the offset slope $\left(S_{o}\right)$. 
2 ). The real fault is supposed to be in the zone between the upper and the lower fault lines. Assuming that the original channel represented by the upstream reach (or the downstream reach) is displaced along the lower fault line (or the upper fault line, respectively), the upstream line is extended to the lower fault line, and the length of the lower fault line from this intersecting point to the intersecting point with the downstream line is taken as $\Delta h_{d}$. The vertical component of offset slope along the lower fault line, $\Delta v_{d}$ (then $S_{o d}$ ), is the height difference between the extended upstream line and the downstream line at the lower fault line on the projected profile graph. The slope of the upstream line drawn on the graph of longitudinal profile along the channel is taken as the channel gradient $\left(S_{c u}\right)$. The assumed channel offset along the lower fault line is represented by $S_{c u}, \lambda_{u}, \Delta h_{d}$ and $\Delta v_{d}$. The same procedure is repeated for the downstream reach with $S_{c d}, \lambda_{d}, \Delta h_{u}$ and $\Delta v_{u}$. The measured/calculated values of offset channel properties are compiled in Table 1.

\section{Miura Peninsula}

Many active faults occur on Miura Peninsula, about $45 \mathrm{~km}$ south of Tokyo (Figure 1). In the developing suburban area of Tokyo, however, finding a stream without serious artificial modification is very hard, and only one offset channel is reported here. A small stream (labeled Kitatake in this study) flowing across the Kitatake fault, which traverses Miura Peninsula with dextral and northeast-upthrown displacement (Kaneko 1969), is offset about 35 52 m ( $\Delta h \approx$ $35 \sim 52 \mathrm{~m}$ ) along the fault (Figure 3 ). Two great earthquakes shaking this area in 1703 and 1923 are rather well known (Matsuda et al. 1978), but historical records of coseismic displacement of the Kitatake fault are not known. The rate of fault displacement is roughly estimated as $>3 \mathrm{~mm} /$ year horizontally, and $>0.4 \mathrm{~mm} /$ year vertically over the past 6,000 years (Williams 1983). The angle of deflection $(\theta)$ measures about $41^{\circ}$ and $\lambda \approx-21 \sim-0.9^{\circ}$. The longitudinal profile of the offset reach has steps and these steps make the offset reach steeper than adjacent reaches, while the tread of each step has a similar gradient to the upstream and downstream reaches (Figure 3). Judging from a small waterfall formed on the nearly vertical bedding plane of the Tertiary sandstone layers downstream from the measured reach, these steps reflect the bedding of the bedrock (alternation of Tertiary sandstone and mudstone). The calculated value of offset slope $\left(S_{o} \approx 0.059 \sim 0.077\right)$ is slightly larger than the channel gradient $\left(S_{c} \approx 0.049 \sim 0.054\right)$.

\section{Neo Valley}

The Neo Valley in Gifu Prefecture, central Japan (Figure 1), is well known for the large Neo-dani fault system that caused the devastating Nobi earthquake in 1891 (e.g., Matsuda 1974). The Neo-dani fault system has an overall trend of sinistral horizontal displacement. The well-known large vertical displacement of the Midori fault scarp (about $6 \mathrm{~m}$ with some sinistral offset), which cut through Mesozoic mudstone and fluvial terrace deposits, appeared as one of the side escarpments of a small triangular islandlike horst produced by horizontal movements of land blocks at the time of the earthquake (e.g., Iseki and Moriya 1968; Okada and Matsuda 1992). The complicated fault distribution and artificial river works, however, make it difficult to identify streams of simple offset by a strike-slip fault in this valley. Only one offset channel is reported here, although some deformed streams were measured.

Koudoko Creek (labeled Koudoko) is a small stream flowing across the strike-slip Neo-dani fault near the Naka settlement. This part of the Neo-dani fault is well known for its large sinistral horizontal displacement (up to $9 \mathrm{~m}$ without vertical displacement) at the time of the Nobi earthquake (Okada and Matsuda 1992). The offset length $(\Delta h)$ is estimated as $28 \sim 32 \mathrm{~m}$ with $\theta \approx 30^{\circ}$, and the flow direction towards the fault is diagonal by $\lambda \approx-21 \sim-32^{\circ}$ (Figure 4 ). The gradient of the offset reach is lower than the adjacent reaches, and the calculated values of $S_{0}$ $(\approx 0.035 \sim 0.039)$ are smaller than $S_{c}(\approx 0.18 \sim$ $0.20)$ reflecting the horizontal nature of fault displacement.

\section{Izu Peninsula}

The strike-slip Irozaki fault trends from southeast to north-west through the southern tip of Izu Peninsula about $150 \mathrm{~km}$ south-west of Tokyo (Figure 1). Dextral displacement of up to $45 \mathrm{~cm}$ 

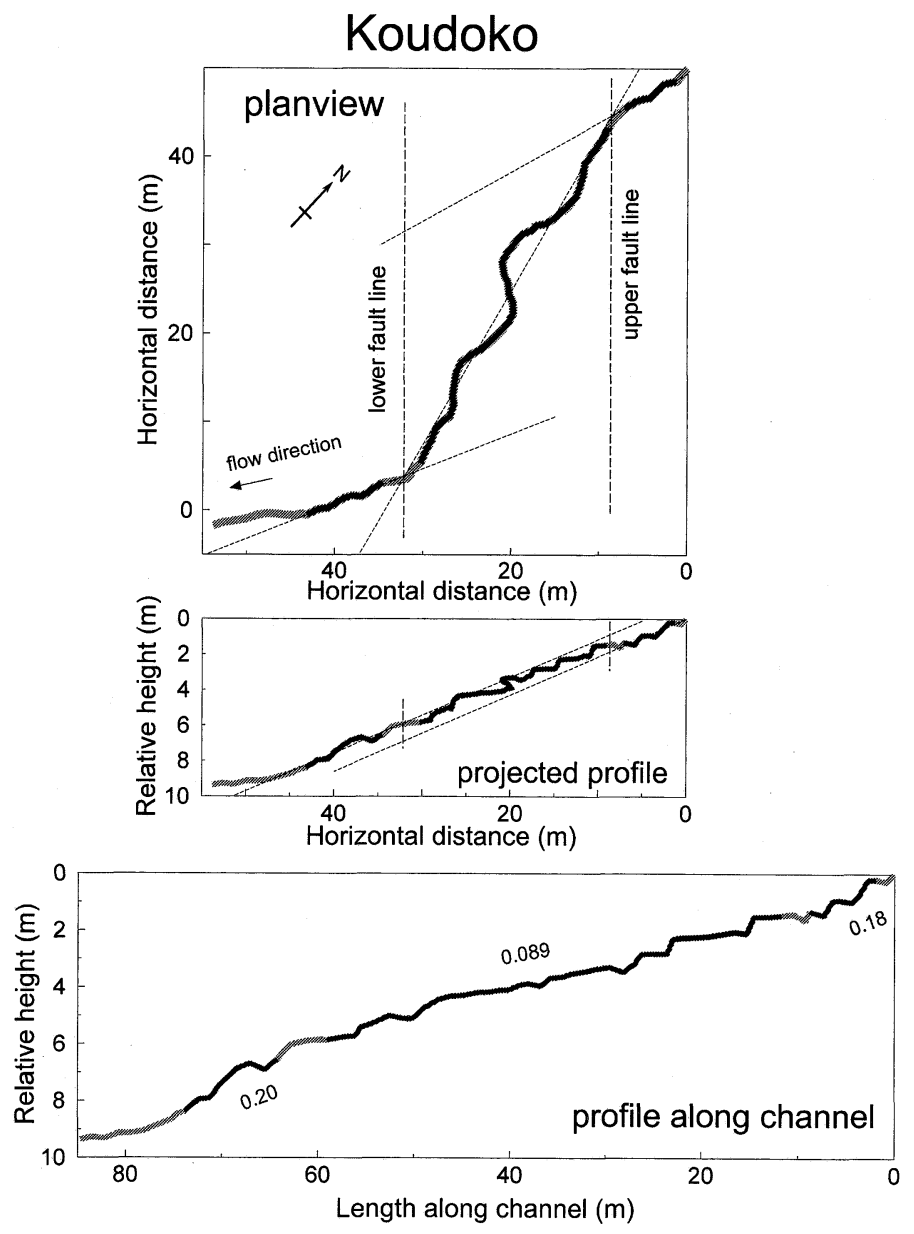

Figure 4. Channel course geometry and longitudinal profiles of Koudoko in the Neo Valley. See Figure 3 for details.

occurred along this fault at the time of the IzuHanto-Oki earthquake in 1974 (Matsuda and Yamashina 1974). A stream near the Yoshida settlement (labeled Yoshida) flows across the northwestern extension of this fault with an apparent dextral offset (Murai and Kaneko 1974). The offset length $(\Delta h)$ is estimated to be about $133 \mathrm{~m}$, and the angle of deflection $(\theta)$ measures about $38^{\circ}$, and $\lambda \approx 21^{\circ}$ (Figure 5 ). The stream is flowing on resistant Tertiary volcanic rocks and has a local concavity in the longitudinal profile in the offset reach. The calculated value of offset slope ( $S_{o} \approx 0.031 \sim 0.032$ ) is smaller than the channel gradient $\left(S_{c} \approx 0.12\right)$.

In central Izu Peninsula, a small and steep stream (labeled Yugashima) flowing into the Nekko River (a tributary of the Kano River) near
Yugashima Town has a clear dextral offset $(\Delta h \approx$ $126 \sim 138 \mathrm{~m}$ ), where it flows across the MizunukiYoichizaka fault $\left(\theta \approx 52^{\circ}\right.$ and $\lambda \approx 30 \sim 36^{\circ}$ ) (Figure 5). Unfortunately, activities of this fault are not known. The channel floor consists mostly of the resistant Tertiary volcanic rocks and the fault gouge is exposed on the valley side at the upstream elbow of the offset reach. The calculated value of $S_{o}(\approx 0.059)$ is much smaller than the channel gradient $\left(S_{c} \approx 0.18 \sim 0.19\right)$.

\section{Shikoku Island}

In Tokushima Prefecture, eastern Shikoku Island, the Median Tectonic Line runs along the northern side of the Yoshino River valley (Figure 1). The Median Tectonic Line, which is the longest fault zone in Japan extending more than 

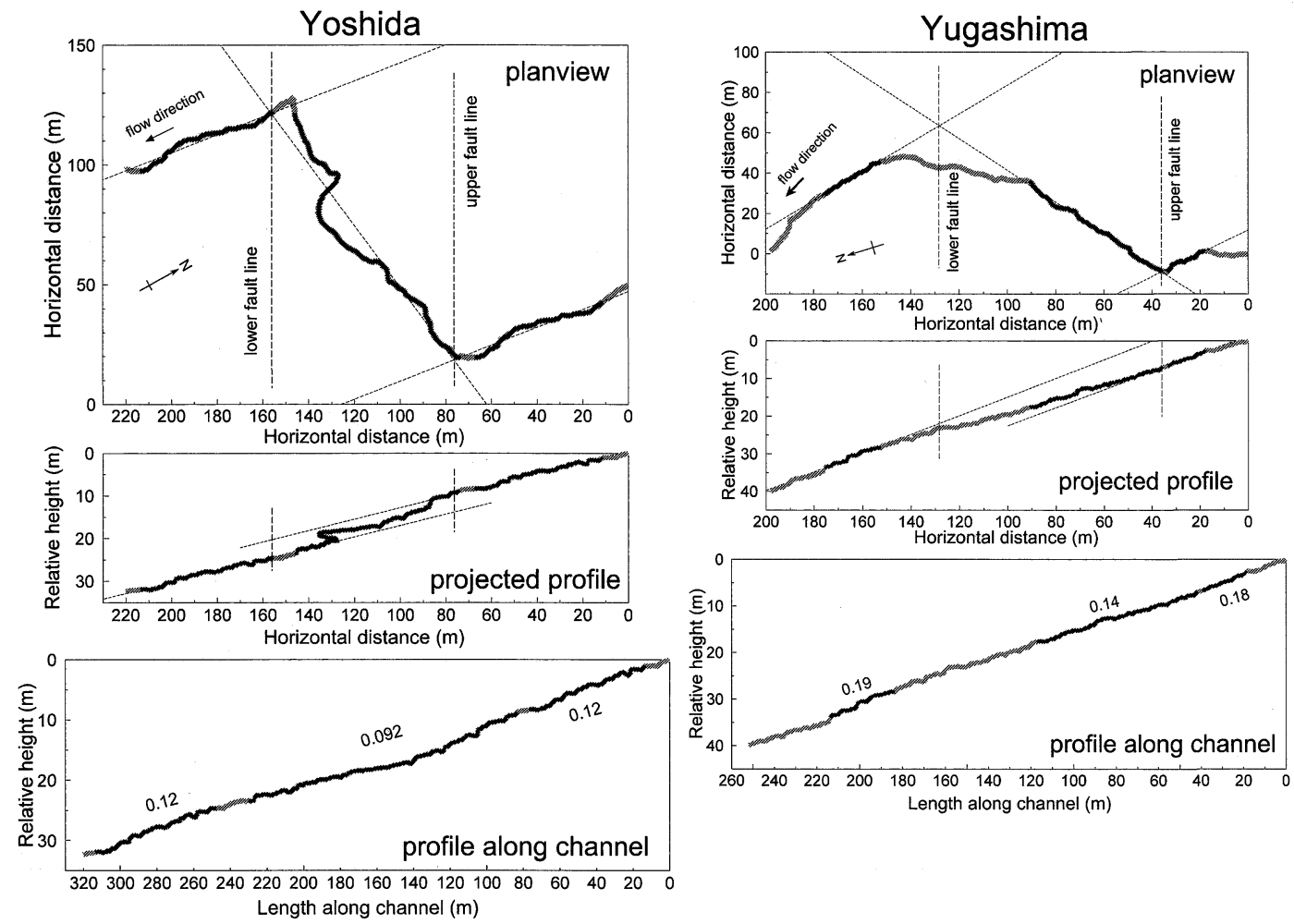

Figure 5. Channel course geometry and longitudinal profiles of Yoshida and Yugashima on Izu Peninsula. See Figure 3 for details.

$300 \mathrm{~km}$, does not appear on the surface as a simple continuous fault but as a series of many shorter dextral strike-slip faults separated by a variety of discontinuities (e.g., Tsutsumi and Okada 1996). Although the last fault displacement in this area is traced way back to the $16^{\text {th }}$ century (e.g., Okada and Tsutsumi 1997), fault activities are considered rather intense as indicated by numerous tectonically deformed landforms, such as offset streams, sag ponds and shutter ridges (e.g., Okada 1970; Tsutsumi and Okada 1996). Most of the channels offset by faults in this area, however, are artificially modified; and moreover, even along offset channels of little artificial modification dense vegetation and steep slopes obstructed measurements. Only three offset channels (labeled Mima, Waki and Awa) could be measured and reported in this study. Mima is a small and steep stream offset by the Mino fault (e.g., Goto and Nakata 2000) located east of the Ikenoura settlement, Mima City. Along the fault zone a trench-like depression, in which abandoned paddy fields are ob- served, is apparent. The upper part of the offset reach and the lower part of the upstream reach look modified for the paddy field (Figure 6), and this section is excluded in the analysis. The offset length is relatively short $(\Delta h \approx 28 \sim 39 \mathrm{~m})$ with the angle of deflection $\theta \approx 30^{\circ}$. The offset reach has a lower gradient than the adjacent reaches and a slight convexity with the offset reach at its center is apparent in the longitudinal profile along channel (Figure 6). The offset slope $\left(S_{o}\right)$ is calculated as $0.005 \sim 0.031$, which is much lower than the channel gradients $\left(S_{c} \approx 0.19 \sim\right.$ 0.23 ). Waki is a tributary channel of the Kurokita valley north of Wakimachi town, Mima City, offset by the Chichio fault (e.g., Tsutsumi and Okada 1996; Goto and Nakata 2000) near its western end. This is the steepest channel reported in this study $\left(S_{c} \approx 0.26 \sim 0.40\right)$. The offset length $(\Delta h)$ is calculated as $105 \sim 117 \mathrm{~m}$, with the large angle of deflection $\left(\theta \approx 62^{\circ}\right)$ and $S_{o} \approx 0.013 \sim$ 0.18 . Its longitudinal profile shows a clear convexity around the offset reach (Figure 6). This convexity appears in the field as a knickpoint at 

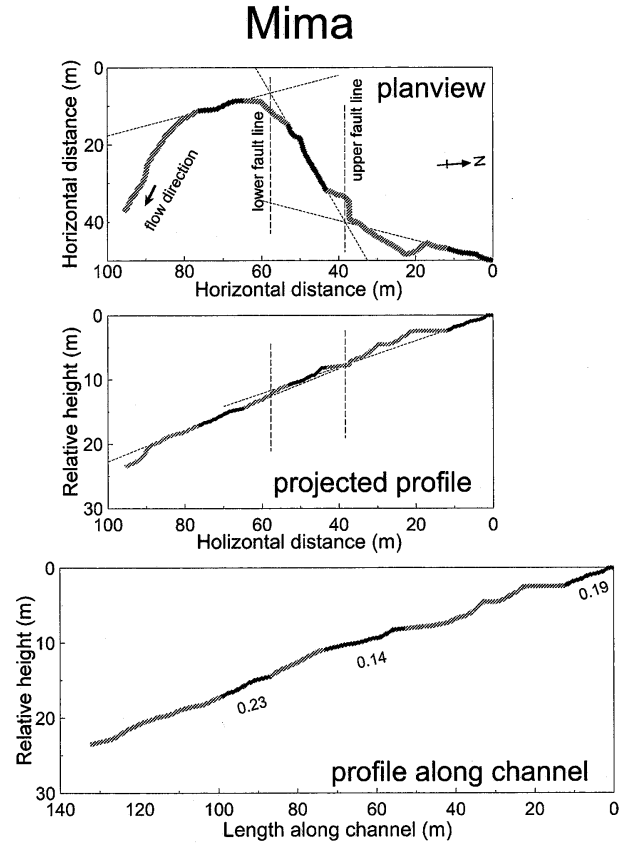

Awa
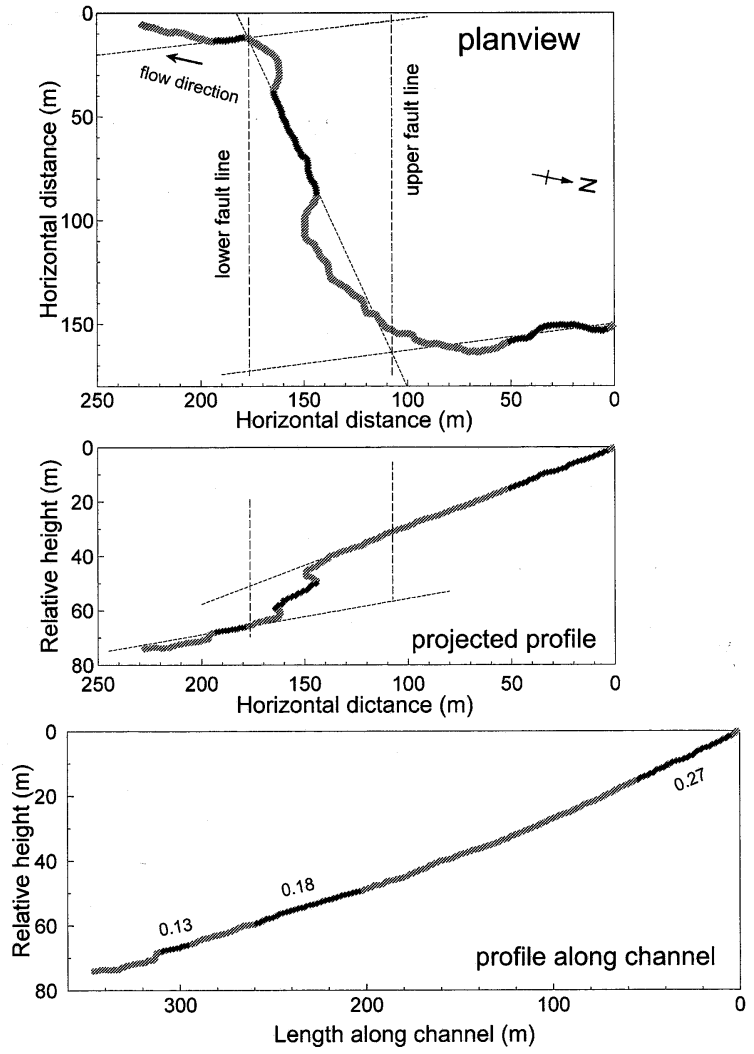

Figure 6. Channel course geometry and longitudinal profiles of Mima, Waki and Awa on Shikoku Island. See Figure 3 for details.
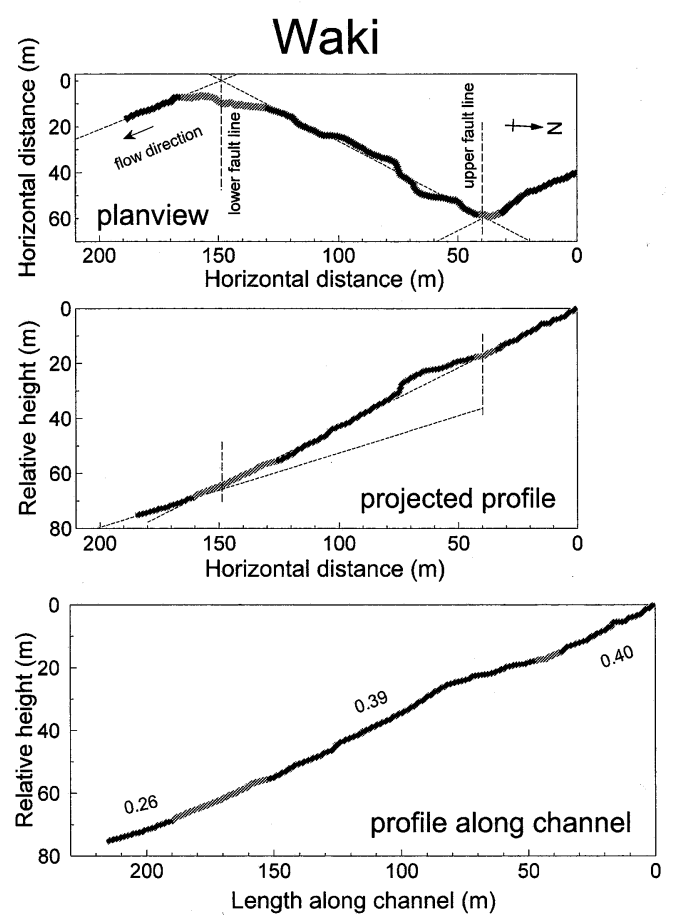
the lower end of the flat and wide section about $30 \mathrm{~m}$ downstream from the upper bend. Awa is a stream called Hiyoshi River behind the Shin-Awa Country Club, Awa Town, and it is offset also by the Chichio fault. Its longitudinal profile is relatively smooth, while the channel course in the planview shows some irregularities especially in the sections including the upper and lower bends (Figure 6). A low step in the lowest part of the downstream reach is a small artificial dam for drawing water, and this section is excluded from the analysis. The calculated offset length is the longest $(\Delta h \approx 160 \sim 161 \mathrm{~m}$ ) among the offset channels reported in this study, while the angle of deflection is rather small $\left(\theta \approx 25^{\circ}\right)$. The obtained offset slope $\left(S_{0} \approx 0.16 \sim 0.092\right)$ does not differ much from the channel gradient $\left(S_{c} \approx\right.$ $0.13 \sim 0.27$ ).

\section{Discussion}

\section{Offset length and fault slip rate}

Matsuda (1966) observed a rough relationship on a log-log plot between the amount of river offset (D) and channel length upstream from the fault (L), along the Atotsugawa fault in central Japan. Matsuda (1975) then estimated the average rate of strike-slip (S) for the Irozaki fault in Isu Peninsula from the relationship between $\mathrm{S}$ $\left(\mathrm{m} / 10^{3} \mathrm{y}\right)$ and $\mathrm{D} / \mathrm{L}, \mathrm{S} \sim 10(\mathrm{D} / \mathrm{L})$, calculated for the faults of relatively well-known activities. Despite the lack of statistical verification, the relationship between D and L, and the method to estimate the average rate of strike-slip fault displacement from $\mathrm{D} / \mathrm{L}$, have been widely accepted in Japan (e.g., Okada 1970; Ando 1972; Okada and Sangawa 1978; Fukui 1981; Yoshioka 1986; Uemura 1988). Figure 7a shows the relationship between offset length $(\Delta h)$ and channel length above the fault line to the divide $(L)$, including offset channels crossing the San Andreas fault reported by Ouchi (2005). Japanese offset streams as well as the older offset channels crossing the San Andreas fault do not show any correlations between $\Delta h$ and $L$, while small gullies cutting flat surfaces of alluvial fans or pediments in the Carrizo Plain show a relatively good correlation. The relationship between $\mathrm{D}$ and $\mathrm{L}$ pointed out by Matsuda (1966), which corre- sponds to the relationship between $\Delta h$ and $L$, does not seem valid for Japanese offset streams measured in the field in this study. In California, Gaudemer et al. (1989) demonstrated a correlation between the apparent offset length and the river length upstream from the fault determined on $1: 250,000$ maps, and inferred the slip rates of some faults using the estimated rates of river elongation taken from the literature. They obtained the values of fault slip rate well above the rates generally accepted, and concluded that the river offset does not indicate actual tectonic displacement. However, besides the possibility that the rate of river elongation they employed is inappropriate, this conclusion may have resulted from factors other than fault displacement. The apparent river "offsets" measured on small scale maps may probably reflect other geomorphologic factors such as the difference in spacing of rivers by size, more than the offset by fault displacement. The vague relationship between $\mathrm{D}$ and $\mathrm{L}$ for offset rivers in Japan (e.g., Matsuda 1966) may also reflect something other than the offset by fault displacement. In order to recognize offset channels as an indicator of fault displacement, closer examinations of the individual offset channels are apparently needed. Ouchi (2005) suggested that the offset length of an offset channel without a trace of serious fluvial disturbance, such as avulsion or capture, indicates the amount of fault displacement the channel has taken. All the offset streams reported in this study show no trace of channel avulsion or stream capture. The offset length $(\Delta h)$ of these streams can be considered here to represent the amount of fault displacement they have taken. In the same manner as the relation between $\Delta h$ and $L$, no correlations between $\Delta h$ and drainage area above the fault line $(A)$ is observed for these Japanese offset streams and the older offset channels crossing the San Andreas fault, while small offset gullies in the Carrizo Plain again show a relatively good correlation (Figure $7 \mathrm{~b}$ ). The drainage area above the fault line $(A)$ is a variable similar to the channel length but more appropriate as an indicator of fluvial ability. The similar relation is also clear between $\Delta h$ and $S_{c} \times L$, which is equivalent to the SL index of Hack (1973) representing stream power (Figure 7c). Ouchi (2005) considered the relatively good 

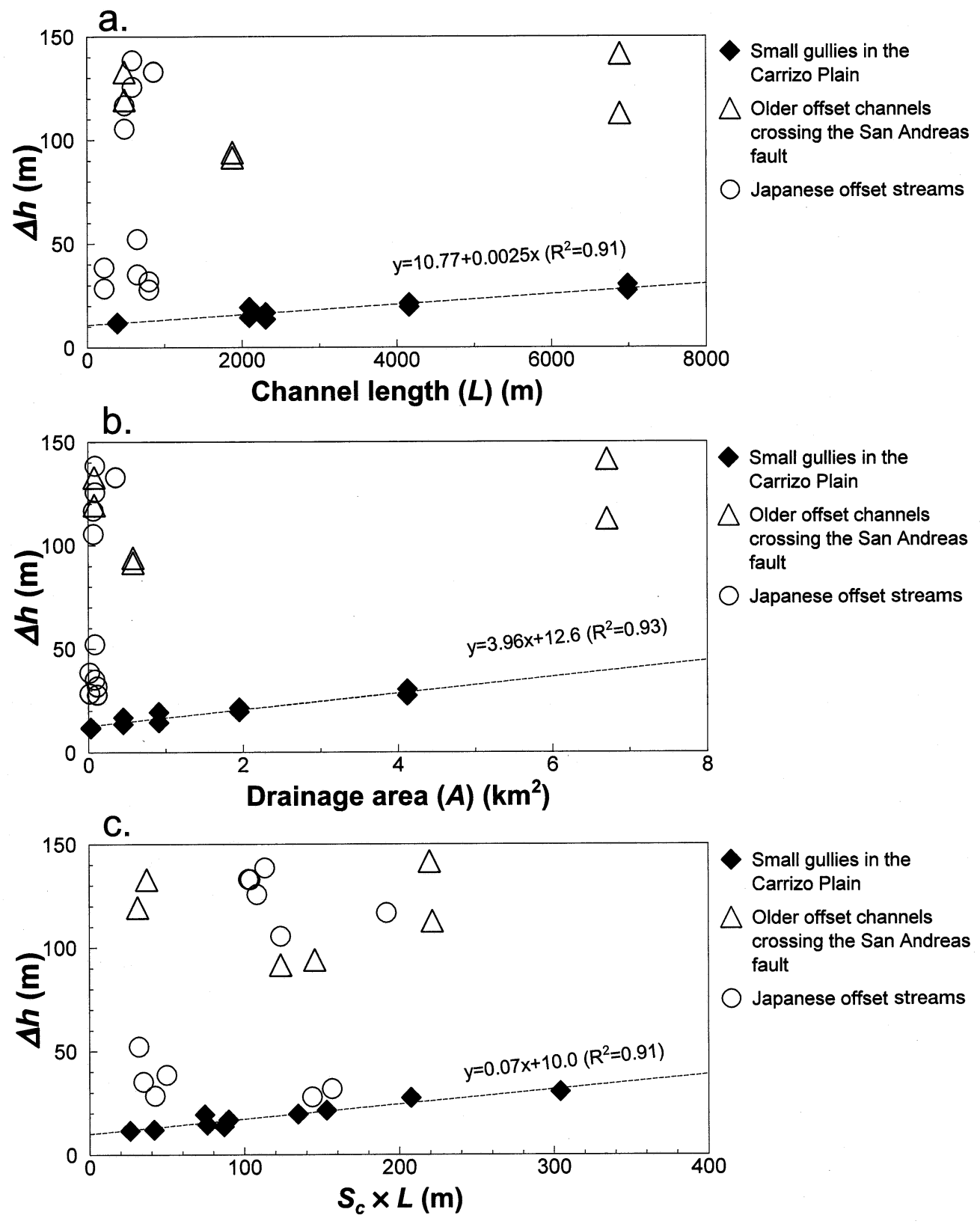

Figure 7 Relationship between offset length $(\Delta h)$ and $\mathbf{a}$. channel length above the fault line $(L)$, b. drainage area above the fault line $(A)$, and c. $S_{c} \times L$, which represents stream power. The regression lines (broken lines) are drawn for the plots of the small offset gullies in the Carrizo Plain, California.

correlation between $\Delta h$ and $A$ or $S_{c} \times L$ for the small offset gullies in the Carrizo Plain as an indication that the gullies with larger drainage area or stream power can keep gullies entrenched longer and therefore offset by the fault longer. This interpretation is possible because small gul- lies in the area are considered to have histories of entrenching and filling (e.g., Bull 1997), and because they are crossing the same segment of a well studied fault. Japanese offset streams and the older offset channels crossing the San Andreas fault are long-lasting features, and their 
drainage area or stream power apparently does not indicate the duration of channel existence. Japanese offset streams reported in this study, moreover, are crossing different faults or fault segments, each of which has its own history and slip rate. The relationship between $\mathrm{D}$ and $\mathrm{L}$ found by Matsuda (1966) seems too vague, and it is probably inappropriate at the present stage to estimate fault slip rates from the values of $\mathrm{D} / \mathrm{L}$ or $\Delta h / L$. This type of relationship is effective only for offset channels whose drainage area or channel length above the fault indicates the duration of channel existence like the small offset gullies in the Carrizo Plain. Moreover, the offset channels should cross the faults of similar slip rates estimated from the evidence other than offset channels.

\section{Angle of deflection}

Huang (1993) assumed that the angle of deflection of an offset channel increases as a way of channel adjustment towards a straight course. In the case where a fault has some thickness (fault zone or shattered zone), which is probably the common case, however, the angle of deflection can be large from the outset of channel offset by faulting. The wider the fault (or shattered) zone and/or the smaller the amount of channel offset, the larger the angle of deflection can be. Unfortunately, fault zone width could hardly be measured; and therefore, the distance between upper and lower fault lines ( $W$ in Figure 2) is considered here as a possible surrogate. By the definition of this study, the angle of deflection $(\theta)$ is geometrically determined by $\Delta h$ and $W$ as $\tan \theta=W / \Delta h$, or offset length $(\Delta h)$ by $W$ and $\boldsymbol{\theta}$ as $\Delta h=W \cot \boldsymbol{\theta}$, if the original channel crosses the fault perpendicularly $(\lambda=0)$ (cf. Figure 2). Different from the actual fault zone width peculiar to each fault segment, however, the value of $W$ inevitably includes the effect of fluvial processes. This makes the geometrical relationship among $\Delta h, \theta$ and $W$ difficult to interpret. Assuming that offset length $(\Delta h)$ reflects the duration of channel offset, larger $\Delta h$ implies a longer time for fluvial adjustment and probable increase in $\theta$. The geometrical relationship, however, indicates that the increase of $\Delta h$ makes $\theta$ decrease if the distance between upper and lower fault lines $(W)$ remains constant. In the simple geometrical relationship with $\lambda=0$ $(\Delta h=W \cot \theta)$, the value of $\Delta h$ decreases with the increase of $\theta$ as a cotangent function when $W$ remains constant, and $\Delta h$ increases linearly with $W$ if $\boldsymbol{\theta}$ does not change. In the common case of $\lambda \neq 0$, the relation becomes more complicated as $\tan \theta=W /(\Delta h-W \tan \lambda)$ or $\Delta h=W(\cot \theta+$ $\tan \lambda)$, but the similar explanation may still be expected, although it becomes more obscure. The obtained values of $\theta$ are mostly smaller than $45^{\circ}(>0)$ and almost all the values of $\lambda$ are in the range of $-45^{\circ}<\lambda<+45^{\circ}$ (especially, $-31.8^{\circ} \sim 35.5^{\circ}$ for Japanese offset streams) (Table $1)$. This makes $\tan \lambda$ less influential than $\cot \theta$, because the absolute value of cotangent is larger, possibly much larger, than that of tangent in the range between $-45^{\circ}$ and $+45^{\circ}$, by the characteristics of tangent and cotangent functions.

Offset channels reported in this study and those in Ouchi (2005) can be categorized into three groups according to the relation of $\theta$ (or $W$ ) to $\Delta h$ (Figure 8), although no correlation is clear in the graph as a whole. The first is a group of small offset gullies in the Carrizo Plain and Japanese offset streams of small $\Delta h$ (Kitatake, Koudoko and Mima), the second group is the older offset channels crossing the San Andreas fault, and the third group is the Japanese offset streams of relatively large $\Delta h$ (Yoshida, Yugashima, Waki and Awa). The small offset gullies in the Carrizo Plain of the first group have their $W$ values within a relatively narrow range and show no correlation between $W$ and $\Delta h$, indicating that their $W$ roughly represents the fault zone width of this segment possibly with some incipient fluvial disturbance. Their short offset length makes their angle of deflection relatively large and probably makes them vulnerable to fluvial disturbance. The significant channel shift towards a straighter course (actually, towards the steepest possible course, as discussed in the next section), which increases $\theta$ (and probably $W$ ), has not occurred yet, due to the short time for fluvial adjustment indicated by their small $\Delta h$. The Japanese offset streams of small $\Delta h$ cross different faults and have a wider variety of $W$ values, but a similar explanation can still be applied to each of them. The second group of the older offset channels crossing the San Andreas fault, on the other hand, have the value of $\boldsymbol{\theta}$ 

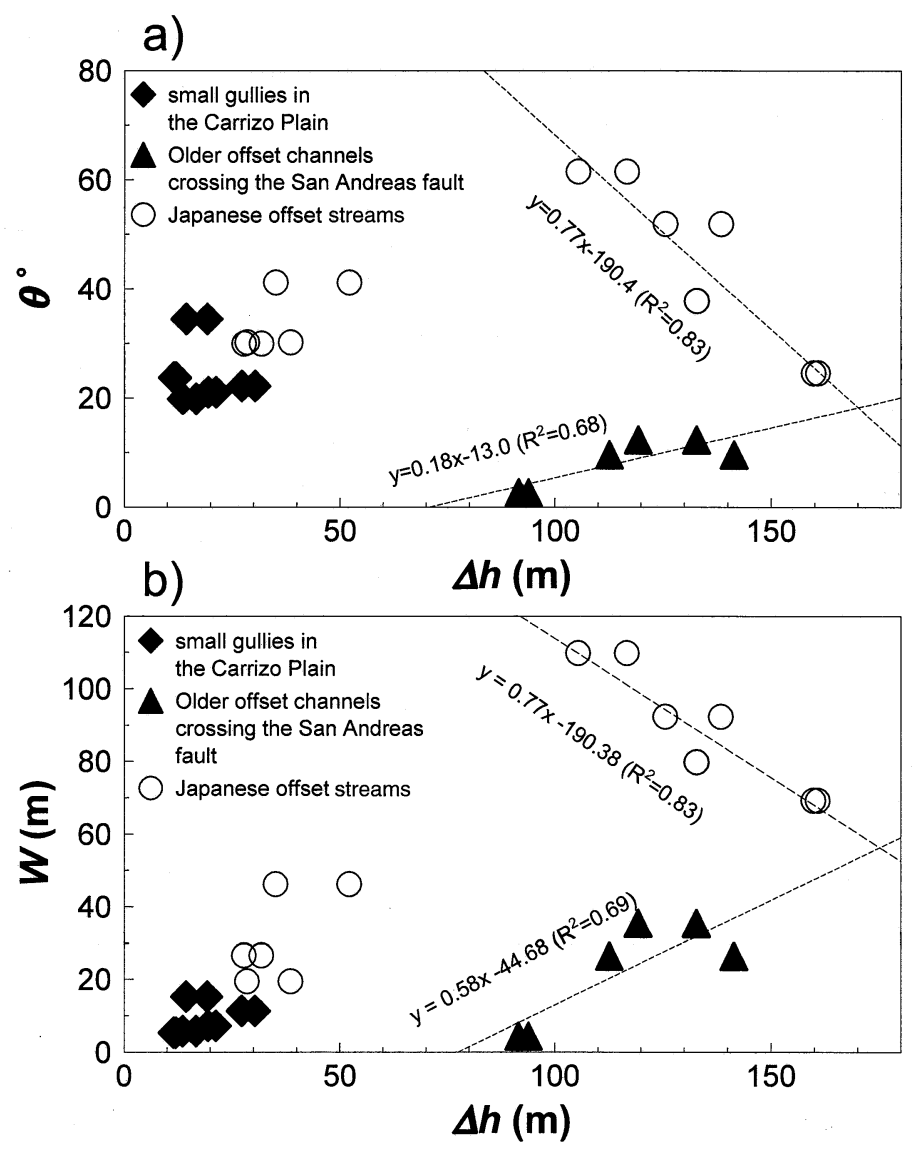

Figure 8 Relationship between a) the angle of deflection $(\theta)$ and offset length $(\Delta h)$ and b) the distance from upper to lower fault lines $(W)$ and offset length $(\Delta h)$. The regression lines (broken lines) are drawn for the plots of the second group (the older offset channels crossing the San Andreas fault) and the third group (Japanese offset streams of long $\Delta h$ ).

(and $W$ ) tending to increase with $\Delta h$. Ouchi (2005) explained this tendency by the increase in $\theta$ as a result of gradual channel shift towards a straighter course for offset channels which could preserve and accumulate their repeated offset for a long time.

For the Japanese offset streams of larger $\Delta h$ (the third group), the value of $\boldsymbol{\theta}$ (and $W$ ) tends to decrease with $\Delta h$ (Figure 8), contrary to the second group. The Japanese offset streams of the third group have relatively large $W$ (and $\theta$ ), while their $\Delta h$ values are similar to those of the second group. The large value of $W$ means a wide fault zone and/or more fluvial adjustment shifting the offset reach towards a straighter course (increase in $\theta$ ). While the large value of $W$ itself may indicate the wide fault zones of Japanese strike-slip faults, the fault zone width does not explain the rough negative correlation between $W$ and $\Delta h$, because fault zone width is considered fundamentally independent from offset length $(\Delta h)$. Fault zone width may possibly increase with fault displacement as Robertson (1983) indicated for the faults observed mainly in mines. However, the offset length $(\Delta h)$ is a variable expressing the amount of channel offset, not the entire amount of fault displacement; and therefore, fault zone width does not necessarily increase with $\Delta h$. On the other hand, the value of $\theta$ (and possibly $W$ ) is supposed to increase with $\Delta h$ as a result of channel shift towards a straighter course, assuming that $\Delta h$ reflects the duration of fluvial adjustment. The fault slip rate is estimated as $33.9 \pm 2.9 \mathrm{~mm} / \mathrm{year}$ for the San 
Andreas fault at Wallace Creek (Sieh and Jahns 1984), and as $5 \sim 10 \mathrm{~mm} / \mathrm{year}$ for faults of the Median Tectonic Line active fault system on Shikoku Island (Okada 1970), which is one of the highest in onshore Japan (Tsutsumi and Okada 1996). The estimated recurrence intervals of Japanese faults (e.g., Tsutsumi and Okada 1996) are much longer than those of the San Andreas fault (e.g., Sieh and Jahns 1984; Grant and Sieh 1994). The amount of fault displacement at one seismic event along an active fault in Japan, moreover, is considered smaller than that along the San Andreas fault (Tsutsumi and Okada 1996). The Japanese offset streams of the third group apparently have a longer time of fluvial adjustment than the second group despite their similar values of $\Delta h$. These Japanese offset streams, however, cross different faults or fault segments of possibly different slip rates, while offset channels of the second group cross the same fault. The difference among the $\Delta h$ values of the third group does not necessarily correspond to the difference in the duration of fluvial adjustment, although the large difference in $\Delta h$ between the first and the third groups can be considered to indicate the difference in the duration of fluvial adjustment or offset by faulting. The rough negative correlation between $\theta$ (or $W$ ) and $\Delta h$ for the Japanese offset streams of the third group shown in Figure 8, which appeared despite the expected wide variety of fault and stream characteristics, seems to require some explanation other than the difference in the duration of fluvial adjustment. The geometrical relationship among $\theta, W$ and $\Delta h(\Delta h=W \cot \theta$, when $\lambda=0$ ), which is considered to hold regardless of the characteristics of faults and streams, may possibly explain the negative correlation between $\theta$ and $\Delta h$ for the third group (Figure 8a). The decrease of $W$ with the increase of $\Delta h$ (Figure $8 \mathrm{~b}$ ), however, cannot be explained by this simple geometrical relationship. Assuming the similar duration of fluvial adjustment, a channel of shorter offset (smaller $\Delta h$ ) considered easier to shift the offset reach towards a straighter course with increasing $\theta$ and therefore $W$ than an offset channel of larger $\Delta h$. In relatively long periods of fluvial adjustment for the Japanese offset rivers of the third group, this tendency may appear as a negative correlation between $W$ and $\Delta h$, over the effects of probable difference in the duration of fluvial adjustment or other characteristics among those offset streams. Steep channels and more frequent floods in Japan (i.e., greater fluvial ability) may also help this tendency to emerge. Moreover, a relatively large decrease of $\theta$ corresponds to a small increase in the value of $\cot \theta$ in the range of large $\theta$ (of the third group), and this possibly enhances the negative correlation between $\theta$ and $\Delta h$.

\section{The steepest possible course of offset reach}

When the fault displacement has a vertical component, the steepest possible course of offset reach can be assumed at a certain angle of deflection. Ignoring incipient channel disturbance and other possible local factors controlling channel morphology, the offset reach will have a gradient $(S)$ determined by the offset slope $\left(S_{o}=\Delta v / \Delta h\right)$, the channel gradient before the deformation $\left(S_{c}\right)$, and the angle of deflection $(\boldsymbol{\theta})$. When the channel is straight and perpendicular to the fault, the gradient of offset reach can be expressed as:

$$
S=\frac{S_{c} \sin \theta(\Delta h / \cos \theta)+\Delta v}{(\Delta h / \cos \theta)}=S_{c} \sin \theta+S_{o} \cos \theta
$$

If $\theta=0$, then $S=S_{o}$, and if $\theta=90^{\circ}, S=S_{c}$. In the common case where the channel is not perpendicular to the fault but diagonal by $\lambda$ (measured in the same direction as $\theta$ from the line perpendicular to the fault) (Figure 2), $\theta$ and $S_{\circ}$ are replaced by $\theta^{\prime}(=\theta-\lambda)$ and $S_{o}^{\prime}\left(=\Delta v^{\prime} / \Delta h^{\prime}\right)$, respectively, where $\Delta h^{\prime}(=\Delta h \cos \lambda)$ and $\Delta v^{\prime}$ $\left(=\Delta h+S_{c} \Delta h \sin \lambda\right)$ are horizontal and vertical components of strike-slip displacement measured perpendicular to the stream direction (Figure 2). The apparent angle of deflection, $\boldsymbol{\theta}^{\prime}$, is the angle of deflection from the line perpendicular to the stream direction. Then, the gradient of offset reach $(S)$ is:

$$
\begin{aligned}
S & =\frac{S_{c} \sin \theta^{\prime}\left(\Delta h^{\prime} / \cos \theta^{\prime}\right)+\Delta v^{\prime}}{\left(\Delta h^{\prime} / \cos \theta^{\prime}\right)} \\
& =S_{c} \sin \theta^{\prime}+S_{o}^{\prime} \cos \theta^{\prime}
\end{aligned}
$$

where

$$
S_{o}^{\prime}=\frac{\Delta v^{\prime}}{\Delta h^{\prime}}=\frac{\Delta v+S_{c} \Delta h \sin \lambda}{\Delta h \cos \lambda} .
$$


Equation (1) can be rewritten as:

$$
S=\sqrt{S_{c}^{2}+S_{o}^{2}} \sin (\theta+\alpha),
$$

where

$$
\cos \alpha=\frac{S_{c}}{\sqrt{S_{c}^{2}+S_{o}^{2}}}, \text { and } \sin \alpha=\frac{S_{o}}{\sqrt{S_{c}^{2}+S_{o}^{2}}} .
$$

Equation (3) indicates that the steepest possible gradient of offset reach is $\sqrt{S_{c}{ }^{2}+S_{o}{ }^{2}}$ when $\sin (\theta+\alpha)=1$. Let $\theta_{\mathrm{sp}}$ be the deflection angle of the imaginary steepest possible course, an offset reach can take the highest gradient of $S=\sqrt{2} S_{c}$ at $\theta_{\mathrm{sp}}=45^{\circ}$ when $S_{c}=S_{o}$, because $\cos \alpha=1 / \sqrt{2}$ and $\alpha=45^{\circ}$. For a stream with $S_{c}>S_{o}$ (and $\Delta v>0$ ) the steepest possible course of offset reach is in the range of $45^{\circ}<\theta_{\mathrm{sp}}<90^{\circ}$, and with $S_{c}<S_{o}$ in the range of $0^{\circ}<\theta_{\mathrm{sp}}<45^{\circ}$. When $\Delta v=0 \quad\left(S_{o}=0\right)$, the steepest possible $S$ would be $S_{c}$ at $\theta_{\mathrm{sp}}=90^{\circ}$. In the more general case in which $\lambda$ is not $0, \theta^{\prime}$ $(=\theta-\lambda), \theta_{\mathrm{sp}}{ }^{\prime}\left(=\theta_{\mathrm{sp}}-\lambda\right)$ and $S_{\circ}{ }^{\prime}$ should replace $\theta, \theta_{\mathrm{sp}}$ and $S_{o}$ respectively in the calculation. Then,

$$
S=\sqrt{S_{c}^{2}+S_{o}^{\prime 2}} \sin \left(\theta^{\prime}+\alpha\right),
$$

where

$$
\cos \alpha=\frac{S_{c}}{\sqrt{S_{c}{ }^{2}+S_{o}^{\prime 2}}}, \text { and } \sin \alpha=\frac{S_{o}{ }^{\prime}}{\sqrt{S_{c}{ }^{2}+{S_{o}^{\prime}}^{2}}} .
$$

Streams would take steeper courses if possible; and therefore, the offset reach will shift towards the steepest possible course at $\theta_{\mathrm{sp}}$ $\left(=\theta_{\mathrm{sp}}{ }^{\prime}+\lambda\right)$, not towards a straight course. In the complicated process of stream adjustment, of course, many other factors, such as channel size, bank and bed erodibility, the occurrence of large bank failure, and the frequency and intensity of floods, in addition to the initial channel disturbances, would easily overwhelm this tendency. The steepest possible channel course is considered here as a potential course, towards which an offset stream may possibly try to shift in the process of adjustment. An offset channel does not necessarily increase the angle of deflection towards a straight course as a way of channel adjustment.

The calculated values of $\theta_{\mathrm{sp}}\left(=\theta_{\mathrm{sp}}{ }^{\prime}+\lambda\right)$ for the upstream and downstream reaches of each offset channel are larger than the values of $\boldsymbol{\theta}$, except for Kitatake (Table 1). This means that offset streams analyzed in this study (except for
Kitatake) may not have reached the channel course of potential stability from the view point of adjustment by lateral shift. Kitatake has the angle of deflection $(\boldsymbol{\theta})$ slightly larger than $\theta_{\mathrm{sp}}$ $\left(<45^{\circ}\right)$, which is rather small reflecting the low channel gradient $\left(S_{c} \approx 0.05\right)$. This implies that Kitatake would not shift its offset reach any more towards a straighter course as an adjustment to the offset by fault displacement.

\section{Longitudinal profiles and deformation type}

The channel deformation in response to strikeslip faulting can be classified into three types based on the relative magnitudes of the offset slope $\left(S_{o}\right)$ and the channel gradient $\left(S_{c}\right)$. Type A deformation corresponds to the situation in which the offset slope is smaller than the channel gradient; Type B to the situation in which the two slopes are equal; and Type $\mathrm{C}$ when the offset slope exceeds the channel gradient (Ouchi 2005). According to Ouchi (2005), the average value of $S_{o} / S_{c}$ within the range of $1.1-0.9$ is considered to represent Type $B$, the value smaller than the range represents Type $\mathrm{A}$, and the larger value Type $\mathrm{C}$. The deformation types of offset channels reported in this study are judged as Type A except for Kitatake (Type C). Upstream aggradation and downstream degradation, which are expected to occur due to the damming effect of offset channel (Ouchi 2004), possibly make Type A offset streams relatively easy to obtain a continuous gradient: Type A offset streams, therefore, tend to preserve their offset course better than Type $\mathrm{C}$, because further fluvial adjustment seems to halt once an offset channel obtains a continuous gradient (Ouchi 2004). The smooth longitudinal profile along the channel of Awa indicates the high degree of fluvial adjustment possible for an offset stream of Type A. This advanced fluvial adjustment is also considered responsible for the relatively large value of $S_{o} / S_{c}$ (close to Type B). The longitudinal profile of Waki has a convexity with a knickpoint in its offset reach, which indicates that the degradation is migrating upstream from the downstream reach. This degradation with a knickpoint in the offset reach may possibly mean that the adjustment of longitudinal profile for the Type A offset stream is on the way. Yoshida, Yugashima, Mima and Koudoko preserve gentler 


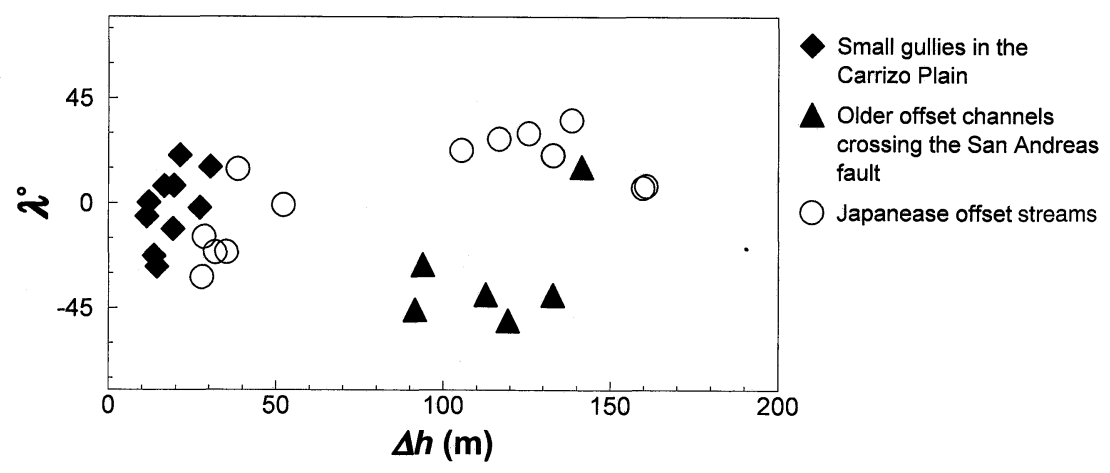

Figure 9 Relationship between crossing angle $(\lambda)$ and offset length $(\Delta h)$.

offset reaches. Judging from their small size and small $\Delta h$, Mima and Koudoko are relatively young offset channels which probably did not have enough time to adjust their longitudinal profiles significantly. Yoshida and Yugashima are both in Izu Peninsula, which is composed mostly of resistant volcanic rocks. The slow incision in their downstream reaches may have resulted in the preservation of low gradients of offset reaches. The local concavity in the offset reach of Yoshida and a slight concavity at the upper part of the offset reach of Yugashime seem to reflect the erodiblility of shattered zone. Kitatake is the only offset stream judged as Type $\mathrm{C}$ in this study. A steeper offset reach tends to remain in the longitudinal profile of a Type $\mathrm{C}$ offset stream probably because of the damming effect of offset channel, and the horizontal shift towards the steepest possible course would progress more than Type A. The steepest possible course of a Type $\mathrm{C}$ offset stream has a smaller value of $\theta_{\mathrm{sp}}$ $\left(<45^{\circ}\right)$, and the $\theta$ value of Kitatake $\left(41^{\circ}\right)$, which exceeds the calculated values of $\theta_{\mathrm{sp}}\left(20 \sim 39^{\circ}\right)$, suggests that no more lateral shift of the offset reach towards a straighter course would occur. The higher gradient of the offset reach probably promoted the tendency of erosion in the reach as indicated by steps reflecting bedding of the bedrock in the longitudinal profile along the channel.

\section{Effects of crossing angle}

Allen (1962) noted that a flow direction nearly perpendicular to the strike of a fault is an important condition for the preservation of stream offsets; otherwise, the stream will follow the zone of fault slip. The values of $\lambda$ range from $-32^{\circ}$ to $36^{\circ}$ for Japanese offset streams, and the range widens to $-50^{\circ} \sim 36^{\circ}$ when including the offset channels crossing the San Andreas fault. The fact that the values of $\lambda$ are mostly within the range of $\pm 45^{\circ}$ may justify the indication by Allen (1962). However, the plot of $\lambda$ versus $\Delta h$ (Figure 9) shows no clear relationship between them. This means that the crossing angle does not seem to determine the duration of channel offset. A small crossing angle (i.e., flow direction close to perpendicular to a fault) may be an important condition to keep the channel offset through a certain initial period while the offset length is still short, and it probably becomes less important once the channel offset survives.

\section{Summary and Concluding Remarks}

Characteristics of seven small offset streams crossing strike-slip faults in central to southwestern Japan were discussed on the bases of longitudinal profiles and channel course geometry measured in the field, especially in comparison with the offset channels crossing the San Andreas fault, California (Ouchi 2005). These offset streams show clear offset along the fault lines in the direction of fault displacement, and their offset length $(\Delta h)$ is considered to represent the amount of channel offset. Japanese offset streams as well as the older offset channels crossing the San Andreas fault do not show any correlations between offset length $(\Delta h)$ and channel length above the fault line $(L)$ or drainage area above the fault line $(A)$, while the small offset gullies in the Carrizo Plain show a 
good correlation. The relation between $\Delta h$ and $S_{c} \times L$, which represents stream power, show the same tendency. The good correlation between $\Delta h$ and $A$ or $S_{c} \times L$ for the small offset gullies in the Carrizo Plain is considered to mean that the drainage area (or stream power) of these gullies indicates the duration of gully entrenchment, in other words, the duration of channel offset by faulting (Ouchi 2005). The drainage area (or stream power) of Japanese offset streams and the older offset channels crossing the San Andreas fault apparently does not indicate the duration of channel existence. The Japanese offset streams, moreover, are crossing different faults of supposedly different slip rates. The method to estimate the average rate of strike-slip fault displacement from offset length and drainage area or channel length above the fault seems valid only for offset channels like the small offset gullies in the Carrizo Plain.

The angle of deflection $(\theta)$, which is the angle between the fault slip direction and the offset reach, is actually determined by fault zone width and the lateral shift of offset reach. The shift of offset reach is supposed to occur towards the steepest possible course at $\theta_{\mathrm{sp}}$, which is determined by the offset slope of fault displacement $\left(S_{o}=\Delta v / \Delta h\right)$ and channel gradient $\left(S_{c}\right)$, not towards a straight course. The angles of deflection of most offset channels are smaller than the deflection angles of the steepest possible courses $\left(\theta_{\mathrm{sp}}\right)$, and this indicates that their channel adjustment by lateral shift has not been completed. The small offset gullies in the Carrizo Plain and the Japanese offset streams of small $\Delta h$ show no correlation between $\theta$ and $\Delta h$. Their values of $\theta$ are probably determined by the fault zone width, not by the shift of offset reach towards the steepest possible course, due probably to their short duration of fluvial adjustment. The older offset channels crossing the San Andreas fault show the increasing trend of $\theta$ with $\Delta h$. This can be explained by the increase in $\theta$ as a result of gradual channel shift towards the steepest possible course for offset channels which could preserve and accumulate their repeated offset for a long time (Ouchi 2005). For the Japanese offset streams of large $\Delta h$, which cross different faults of possibly different slip rates, $\theta$ tends to decrease with $\Delta h$. The offset streams with rela- tively small $\Delta h$ (and/or large $\theta$ ) among them may shift the offset reach (increase $\theta$ ) more easily in similarly long periods of fluvial adjustment, and this tendency may appear as a negative correlation between $\theta$ and $\Delta h$ for these Japanese offset streams of long $\Delta h$.

The deformation types of offset channels reported in this study are judged as Type A, in which the offset slope $\left(S_{o}\right)$ is smaller than channel gradient $\left(S_{c}\right)$, except for Kitatake (Type C). Type A offset streams are considered to obtain a continuous gradient more easily than Type $\mathrm{C}$, due to upstream aggradation and downstream degradation caused by the damming effect of offset channel. The smooth longitudinal profile along the channel of Awa indicates the high degree of fluvial adjustment, and the knickpoint in the offset reach of Waki suggests that the adjustment of longitudinal profile for the Type A offset stream is on the way with the degradation migrating upstream from the downstream reach. Mima and Koudoko, which preserve gentler offset reaches, are considered to be relatively young offset streams. They probably did not have enough time to adjust their longitudinal profiles significantly. In Yoshida and Yugashima, on the other hand, slow incision into the resistant volcanic rocks may have resulted in the preservation of low gradients of offset reaches. A steeper offset reach remains in the longitudinal profile of Kitatake, the only offset stream judged as Type C. The $\boldsymbol{\theta}$ value slightly exceeding the value of $\boldsymbol{\theta}_{\mathrm{sp}}$ of Type $C$ suggests that no more lateral shift of the offset reach towards a straighter course would occur in Kitatake.

Streams crossing strike-slip faults are offset by fault displacement; however, the form of offset channels is highly dependent on fluvial processes working during the recurrence interval. The main fluvial response to the deformation by fault displacement is downstream degradation and upstream aggradation due to the damming effect of offset channels, and lateral shift of offset reach towards the steepest possible course is another important response. The response would halt when the offset stream obtains a continuous gradient, until the next fault displacement deforms the channel. As long as the fault activity continues, offset streams are considered to be always in the repeated process of tectonic de- 
formation and fluvial adjustment.

\section{Acknowledgements}

I thank Dr. Ellen Wohl of Colorado State University, who happened to be in Japan in 1996, Akio Hara, a student of University of Tsukuba at that time, and Hiroyuki Tsuchida, then a student of Chuo University, for their assistance in the preliminary field survey. This study is supported by the Grant-in-Aid for Scientific Research (C) (No. 07808016 and No. 13680107) from the Ministry of Education, Culture, Sports, Science and Technology, Japan, which is gratefully appreciated. I also thank Professor Michael D. Brown of Chuo University for his advice and correction of my English manuscript. Finally, I would like to dedicate this short article to the memory of Professor Dr. Ken'ichi Takahashi of Chuo University, who had been giving me constant encouragement but passed away on the January $7^{\text {th }}, 2006$. Without his understanding and encouragement, I could not have completed this paper. I sincerely pray for the repose of his soul.

(Received 4 October 2005) (Accepted 2 February 2006)

\section{References}

Allen, C. R. 1962. Circum-Pacific faulting in the Philippines-Taiwan region. Journal of Geophysical Research 67: 4795-4812.

Ando K. 1972. Miura-Hanto Izu-Hanto oyobi Hyougoken Yamazaki fukin ni okeru danso no yokozure niyoru tani no hen'i ryou nitsuite (Amount of stream-valley offset caused by strike-slip faulting in Miura and Izu Peninsulas and Yamazaki district). Geographical Review of Japan 45: 716-725. (J)

Bull, W. L. 1997. Discontinuous ephemeral streams. Geomorphology 19: 227-276.

Fukui, K. 1981. Fault topography along the Yamasaki fault system, western Kinki District, Japan. Geographical Review of Japan 54: 196-213. (JE)

Grant, L. B., and Sieh, K. E. 1994. Paleoseismic evidence of clustered earthquakes on the San Andreas fault in the Carrizo Plain, California. Journal of Geophysical Research 99: 6819-6841.

Gaudemer, Y., Taponnere, P., and Turcotte, D. L. 1989. River offsets across active strike-slip faults. $A n$ nales Tectonicce 3: 55-76.

Goto, H., and Nakata, T. 2000. Detailed distribution of active faults along the Median Tectonic Line in Shikoku. Research Center for Regional Geography, Hiroshima University. (JE)
Hack, J. T. 1973. Stream-profile analysis and streamgradient index. Journal of Research, U.S. Geological Survey 1: 421-429.

Huang, H. 1993. Morphologic patterns of stream channels on the active Yishi Fault, southern Shandong Province, eastern China: Implications for repeated great earthquakes in the Holocene. Tectonophysics 219: 283-304.

Iseki, H., and Moriya, I. 1968. Neo-dani danso ni kansuru shiryou (Materials on the Neo-dani fault). Journal of Geography (Chigaku Zasshi) 77: 155-165. (J)

Kaneko, S. 1965. Transcurrent displacement along the Median Line, South-western Japan. New Zealand Journal of Geology and Geophysics 9: 45-59.

Kaneko, S. 1969. Right-lateral faulting in Miura Peninsula, south of Tokyo, Japan. Journal of the Geological Society of Japan 75: 199-208.

Lensen, G. J. 1958. The Wellington fault from Cook Strait to Manawatu Gorge. New Zealand Journal of Geology and Geophysics 1: 178-196.

Matsuda, T. 1966. Strike-slip faulting along the Atotsugawa Fault, Japan. Bulletin of the Earthquake Research Institute 44: 1179-1212. (JE)

Matsuda, T. 1974. Surface faults associated with Nobi (Mino-Owari) earthquake of 1891, Japan. Special Bulletin of the Earthquake Research Institute, University of Tokyo 13: 85-126. (JE)

Matsuda, T. 1975. Active fault assessment for Irozaki fault system, Izu Peninsula. Reports on the Earthquake off the Izu Peninsula 1974, and the Disaster: 121-125. (J)

Matsuda, T., and Yamashina, K. 1974. Surface faults associated with the Izu-Hanto-Oki Earthquake of 1974, Japan. Special Bulletin of the Earthquake Research Institute, University of Tokyo 14: 135-158. (JE)

Matsuda, T., Ota, Y., Ando, M., and Yonekura, N. 1978. Fault mechanism and recurrence time of major earthquakes in southern Kanto district, Japan, as deduced from coastal terrace data. Geological Society of America Bulletin 89: 1610-1618.

Murai, I., and Kaneko, S. 1974. The Izu-Hanto-Oki Earthquake of 1974 and the earthquake faults, especially, the relationship between the earthquake faults, the active faults, and the fracture systems in the earthquake area. Special Bulletin of the Earthquake Research Institute, University of Tokyo 14: 159-203. (JE)

Nakata, T., and Imaizumi, T. eds. 2002. Digital active fault map of Japan. Tokyo: University of Tokyo Press (product serial number: DAFM0724). (J)

Okada, A. 1970. Fault topography and rate of faulting along the Median Tectonic Line in the drainage 
basin of the River Yoshino, northeastern Shikoku, Japan. Geographical Review of Japan 43: 1-21. (JE)

Okada, A., and Matsuda, T. 1992. Late Quaternary activity of the Neodani (Neo-Valley) Fault at Midori and Naka, Neo Village, Central Japan. Journal of Geography (Chigaku Zasshi) 101: 19-37. (JE)

Okada, A., and Sangawa, A. 1978. Fault morphology and Quaternary faulting along the Median Tectonic Line in the southern part of the Izumi Range. Geographical Review of Japan 51: 385-405. (JE)

Okada, A., and Tsutsumi, H. 1997. Holocene activity of the Chichio fault, the Median Tectonic Line active fault system, southwest Japan, based on Trenching studies. Journal of Geolgraphy 106: 644-659. (JE)

Ouchi, S. 2004. Flume experiments on the horizontal stream offset by a strike-slip fault. Earth Surface Processes and Landforms 29: 161-173.

Ouchi, S. 2005. Development of offset channels across the San Andreas fault. Geomorphology 70: 112-128.

Robertson, E. C. 1983. Relationship of fault displacement to gouge and breccia thickness. American Institute of Mining Engineering Transactions 274: 1426-1432.

Sieh, K. E., and Jahns, R. H. 1984. Holocene activity of the San Andreas fault at Wallace Creek, Cali- fornia. Geological Society of America Bulletin 95: 883-896.

The Research Group for Active Faults of Japan 1980. Active Faults in and around Japan: The distribution and degree of activity. Journal of Natural Disaster Science 2: 61-99.

The Research Group for Active Faults of Japan 1991. Active faults in Japan (revised edition). Tokyo: University of Tokyo Press. (JE)

Tsutsumi, H., and Okada, A. 1996. Segmentation and Holocene surface faulting on the Median Tectonic Line, southwest Japan. Journal of Geophysical Research 101: 5855-5871.

Uemura, Y. 1988. Fault topography and Quaternary faulting of the Mitoke fault system in the southwestern part of the Tamba Highland, southwest Japan. Geographical Review of Japan 61A: 453-468. (JE)

Wallace, R. E. 1968. Notes on stream channels offset by the San Andreas fault, Southern Coast Ranges, California. Stanford University Publication, Geological Science 11: 6-20.

Williams, D. N. 1983. Late Quaternary displacement at the Hikihashi and Kitatake faults, Miura Peninsula, Japan. The Quaternary Research 21: 289-299.

Yoshioka, T. 1986. Tectonic topography along the Hanaore fault in the northern Kinki District, Japan. Geographical Review of Japan 59A: 191-204. (JE) 